\title{
Behaviors of Perfluorocarbon Emulsion during Dissolution of Oxide Layers
}

\author{
Naon Chang ${ }^{1,2, *}$, Huijun Won ${ }^{2, *}$, Chonghun Jung ${ }^{2}$, Seonbyeong Kim ${ }^{2}$, Heechul Eun ${ }^{2}$ and Yongsoo Kim ${ }^{1}$ \\ 1 Department of Nuclear Engineering, Hanyang University, 222 Wangsimri-ro, Seongdong-gu, \\ Seoul 04763, Korea; yongskim@hanyang.ac.kr \\ 2 Decommssioining technology research division, Korea Atomic Energy Research Institute, \\ Daedeok-daero 989-111, Yuseong-gu, Daejeon 34057, Korea; nchjung@kaeri.re.kr (C.J.); \\ sbkim@kaeri.re.kr (S.K.); ehc2004@kaeri.re.kr (H.E.) \\ * Correspondence: cno0622@kaeri.re.kr (N.C.); nhjwon@kaeri.re.kr (H.W.); Tel.: +82-428688604 (N.C.); \\ $+82-428682331$ (H.W.)
}

\begin{abstract}
This study investigates the dissolution behavior of oxide layers containing radionuclides using perfluorocarbon (PFC) emulsion as a reusable medium. Chemicals such as PFC, anionic surfactant, and $\mathrm{H}_{2} \mathrm{SO}_{4}$ are used for preparing the PFC emulsion, and emulsified using an ultrasonication process. The FTIR results show $\mathrm{O}-\mathrm{H}$ stretching that is formed by the interaction of the carboxyl group of the anionic surfactant with the hydroxyl group of water containing $\mathrm{H}_{2} \mathrm{SO}_{4}$, and find that the $\mathrm{H}_{2} \mathrm{SO}_{4}$ can be homogeneously dispersed in the PFC-anionic surfactant- $\mathrm{H}_{2} \mathrm{SO}_{4}$ emulsion. The dissolution test of the simulated $\mathrm{Cr}_{2} \mathrm{O}_{3}$ specimen is conducted using $\mathrm{PFC}$ emulsion containing $\mathrm{KMnO}_{4}$. Through the weight losses of specimens and Scanning Electron Microscope-Energy Dispersive X-ray Spectrometer (SEM-EDS) analysis, it is confirmed that the $\mathrm{Cr}_{2} \mathrm{O}_{3}$ layer on the SUS304 specimen is easily dissolved using PFC emulsion. During the dissolution of the $\mathrm{Cr}_{2} \mathrm{O}_{3}$, it is observed that the dispersed $\mathrm{H}_{2} \mathrm{SO}_{4}-\mathrm{KMnO}_{4}$ became unstable and separated from PFC emulsion. Based on these results, the behavior of the PFC emulsion during the dissolution of the oxide layer is explained.
\end{abstract}

Citation: Chang, N.; Won, H.; Jung,

C.; Kim, S.; Eun, H.; Kim, Y.

Behaviors of Perfluorocarbon Emulsion during Dissolution of Oxide Layers. Molecules 2021, 26, 1329. https://doi.org/10.3390/ molecules26051329

Academic Editor: Chan Kyung Kim

Received: 27 January 2021

Accepted: 24 February 2021

Published: 2 March 2021

Publisher's Note: MDPI stays neutral with regard to jurisdictional claims in published maps and institutional affiliations.

Keywords: perfluorocarbon; emulsion; dissolution; oxide layer; decontamination

\section{Introduction}

Nuclear facilities consist of various metal equipment and metal devices. The metal surfaces can be contaminated with oxide layers containing the radionuclides during the operation of nuclear facilities [1,2]. The contaminated metals increase the amounts of radioactive wastes when they are disposed of without treatment. Therefore, the contaminations on the metal surface are necessary to be removed using various decontamination methods to reduce the amount of radioactive waste generation.

The radionuclides on the metal surface can be removed by dissolving them along with the oxide layer using a chemical solution [2,3]. Although the water-based chemical method is commonly used to dissolve the oxide layer, large amounts of radioactive liquid wastes can be generated. The radioactive liquid wastes are necessary to be treated using UV decomposition or ion exchange resins [3,4]. However, during, the treatment of the radioactive liquid wastes, additional costs are needed, and secondary wastes are generated.

To solve this problem, the methods of using perfluorocarbon (PFC) as a medium for removing the contaminants from the metal surface were studied by various researchers. PFC is the liquid used for cleaning the device, manufacturing the semiconductor, and cooling the electronics [5,6]. PFC is composed of carbon and fluorine, and the chemical formula of PFC is $\mathrm{C}_{\mathrm{x}} \mathrm{F}_{\mathrm{y}}$. The boiling point, latent heat, and specific heat of the PFC are generally lower than water [7]. The density of the PFC is commonly higher than water. For instance, the density of PF-5058, which is one of the PFC, is $1.75 \mathrm{~g} / \mathrm{mL}$ [8]. In addition, the PFC has a high radiation resistance [9]. The PFC can be usefully applied to remove the radionuclides from the metal surface due to this feature. 
Kaiser studied the removal of the loosely-attached radioactive particles from the various surface by applying the ultrasonication in the bath filled with PFC and surfactant [10]. It was confirmed that $78.0-99.7 \%$ of contaminants were removed from the surfaces regardless of the type of specimens [10]. Won studied the removal of the contaminants from the metal surface by spraying the PFC and surfactant mixture [11]. As a result, the radioactive particles were removed from the metal surface because the anionic surfactant reduced the adsorption force between the contaminants and metal [11]. These two methods were the physical method for the removal of the contaminants loosely sticking on the metal surface, thus it cannot be applied to the dissolution of the oxide layer with radioactive contaminant fixed on the metal surface. This is because the PFC medium does not mix with the decontamination agent, reacting with the oxide layer. PFC cannot form a homogenous solution after mixing with the polar molecules. To resolve this problem, it is necessary to mix the PFC with the decontamination agent homogeneously.

In order to homogeneously mix the decontamination agent with the PFC, the emulsification can be applied. The emulsification of the PFC and chemicals has been studied by various researchers. Song studied the cancer therapy method using PFC and hydrophobic $\mathrm{TaOx}$ nanoparticles emulsified by an amphiphilic polymer [12]. As a result, the tumor oxygenation and radiotherapy were enhanced by the $\mathrm{O}_{2}$ saturation reaction of PFC emulsion [12]. Flögel developed the in vivo visualization of inflammatory processes by magnetic resonance imaging using biochemically inert PFC nanoemulsions [13]. From the above studies, it was found that the PFC emulsion was utilized as a useful medium in the medical field. It was also confirmed that emulsification was effective in mixing the chemicals homogeneously. Therefore, it is expected that the emulsification method can be applied to mix the PFC medium and decontamination agent. In addition, the decontamination agent dispersed in the PFC emulsion can be separated from the emulsion when the emulsion becomes unstable over time. In this case, the used decontamination agent will be located on the PFC because the density of the PFC is higher than the decontamination agent. For this reason, it is expected that the PFC medium can be easily reused after scooping the decontamination agent and the radionuclides dissolved in the decontamination agent.

In this study, an innovative chemical dissolution method of the oxide layer, P-BED (perfluorocarbon-based emulsion for oxide layer dissolution) composed of recoverable PFC, anionic surfactant, $\mathrm{H}_{2} \mathrm{SO}_{4}$, was designed. The objective of this study is to effectively remove the contaminants and the oxide layers from the metal surface using the P-BED medium and to obtain the behavior of the P-BED during dissolution. The chemical structures and stability of the P-BED were analyzed by FTIR. The dissolution performance of the P-BED containing $\mathrm{KMnO}_{4}$ was evaluated by dissolution test for the simulated $\mathrm{Cr}_{2} \mathrm{O}_{3}$ layers on the SUS304 specimen.

\section{Results and Discussion}

\subsection{Characteristics of the P-BED}

Figure 1 shows the FTIR spectra of pure PFC and the P-BED, consisted of PFC-anionic surfactant $-\mathrm{H}_{2} \mathrm{SO}_{4}$ emulsion, under three different concentrations of $\mathrm{H}_{2} \mathrm{SO}_{4}$. As represented in Figure 1, two peaks appeared at 2880 and $2975 \mathrm{~cm}^{-1}$ in the pure PFC spectrum and also appeared in the spectra of the emulsions. The two peaks were due to the unique characteristic of PFC. In the three types of emulsions, a sharp peak at $3550 \mathrm{~cm}^{-1}$ increased as the concentration of $\mathrm{H}_{2} \mathrm{SO}_{4}$ increased from 0.18 to $0.74 \mathrm{M}$. Hintze identified the O$\mathrm{H}$ stretching spectra near $3600 \mathrm{~cm}^{-1}$ in the vapor-phase sulfuric acid [14]. Therefore, a sharp peak at $3550 \mathrm{~cm}^{-1}$, when the concentrations of $\mathrm{H}_{2} \mathrm{SO}_{4}$ were 0.37 and $0.74 \mathrm{M}$, were considered to be due to $\mathrm{H}_{2} \mathrm{SO}_{4}$. In addition, a broad peak at the range of $3000-3700 \mathrm{~cm}^{-1}$ appeared increased when the $\mathrm{H}_{2} \mathrm{SO}_{4}$ concentration decreased from 0.74 to $0.18 \mathrm{M}$. It was reported that the broad band around $3400 \mathrm{~cm}^{-1}$ is associated with the $\mathrm{O}-\mathrm{H}$ stretching modes of $\mathrm{H}_{2} \mathrm{O}[15,16]$. Based on this result, we could infer that the interaction of each component in PFC emulsions with the hydroxyl peak of water containing $\mathrm{H}_{2} \mathrm{SO}_{4}$. After emulsification, the carboxyl groups of the hydrophilic head of anionic surfactant (Krytox 
157FSM) interact with $\mathrm{H}_{2} \mathrm{O}$, including $\mathrm{H}_{2} \mathrm{SO}_{4}$, and the hydrophobic tail interacts with PFC $[17,18]$. Therefore, the broad peak in the range of $3000-3700 \mathrm{~cm}^{-1}$ could be attributed to the interaction of different bonds between the hydroxyl group of $\mathrm{H}_{2} \mathrm{O}$ and the anionic surfactant and $\mathrm{H}_{2} \mathrm{SO}_{4}$ when the $\mathrm{H}_{2} \mathrm{SO}_{4}$ concentration was $0.18 \mathrm{M}$. Because of these results, it can be determined that the P-BED becomes stable because the bond between PFC, anionic surfactant, and $\mathrm{H}_{2} \mathrm{O}$ containing $\mathrm{H}_{2} \mathrm{SO}_{4}$ increases when $\mathrm{H}_{2} \mathrm{SO}_{4}$ concentration decreases from 0.74 to $0.18 \mathrm{M}$.

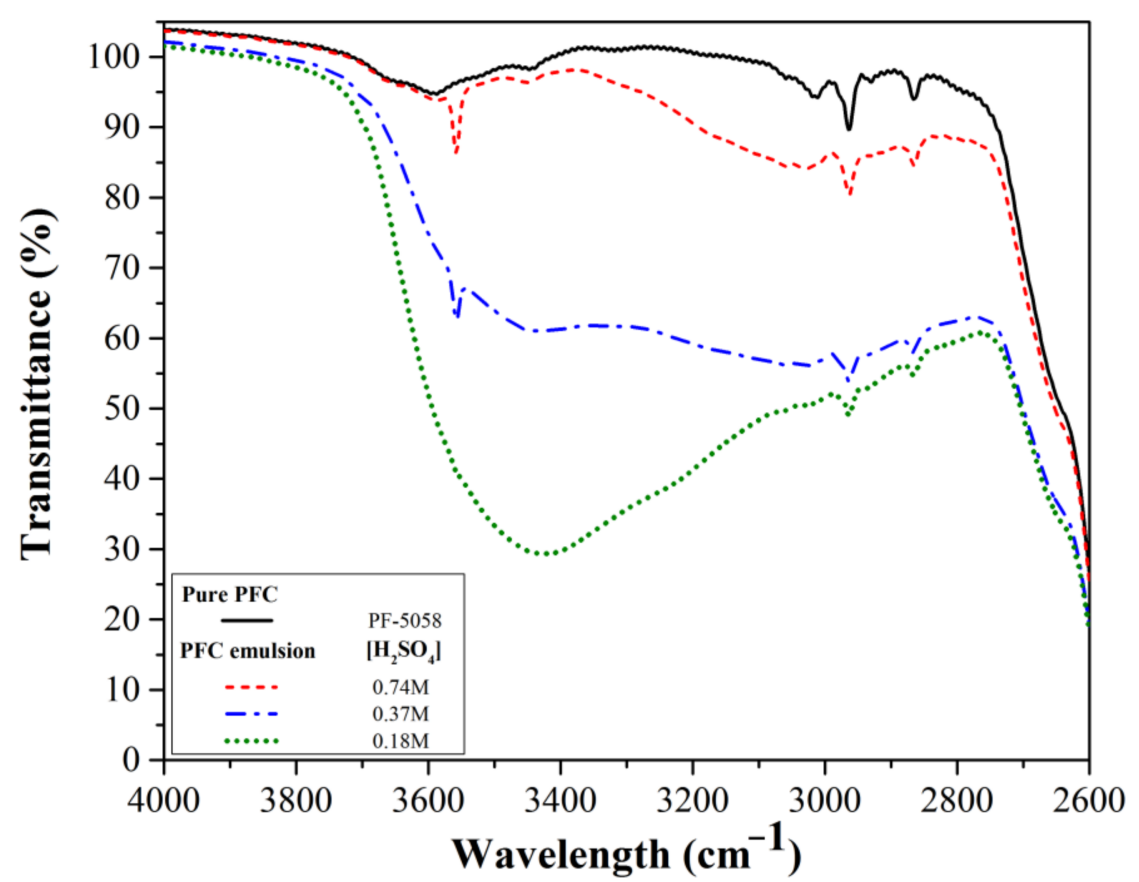

Figure 1. FTIR spectra of the pure perfluorocarbon (PFC) and the P-BED (perfluorocarbon-based emulsion for oxide layer dissolution) consisted of $\mathrm{PFC}$-anionic surfactant- $\mathrm{H}_{2} \mathrm{SO}_{4}$.

The phase change of the P-BED with the times was observed to investigate the dispersion stability of the P-BED. The photographs of P-BED are shown in Figure 2. Flocculation was not observed within $25 \mathrm{~h}$ when the concentrations of $\mathrm{H}_{2} \mathrm{SO}_{4}$ in the emulsion were $0.18 \mathrm{M}$ and $0.37 \mathrm{M}$. On the other hand, the flocculation was observed in the P-BED after $5 \mathrm{~h}$ when the concentration of $\mathrm{H}_{2} \mathrm{SO}_{4}$ in the P-BED was $0.74 \mathrm{M}$. It is considered that the flocculation is happened when the emulsion becomes unstable [19]. Therefore, $0.74 \mathrm{M}$ of $\mathrm{H}_{2} \mathrm{SO}_{4}$ was not suitable for the condition of P-BED.

\subsection{Dissolution Characteristics of the Oxide Layer Using P-BED}

Before the dissolution test, the simulated oxide layer on the SUS304 specimen was prepared. The surface morphologies of the SUS304 specimen, before and after the hightemperature oxidation, are shown in Figure 3. Figure 3 also shows the crystalline particles formed on the specimen surface after the oxidation. The particles were an octahedral shape, with a diameter of between $100-400 \mathrm{~nm}$, and were aligned along the linear grooves that were formed during grinding. From the Energy Dispersive X-ray Spectroscopy (EDS) result, the oxide layer mainly composed of $\mathrm{Cr}_{2} \mathrm{O}_{3}$, and the content of oxygen of the oxide layer was $61.33 \%$. 


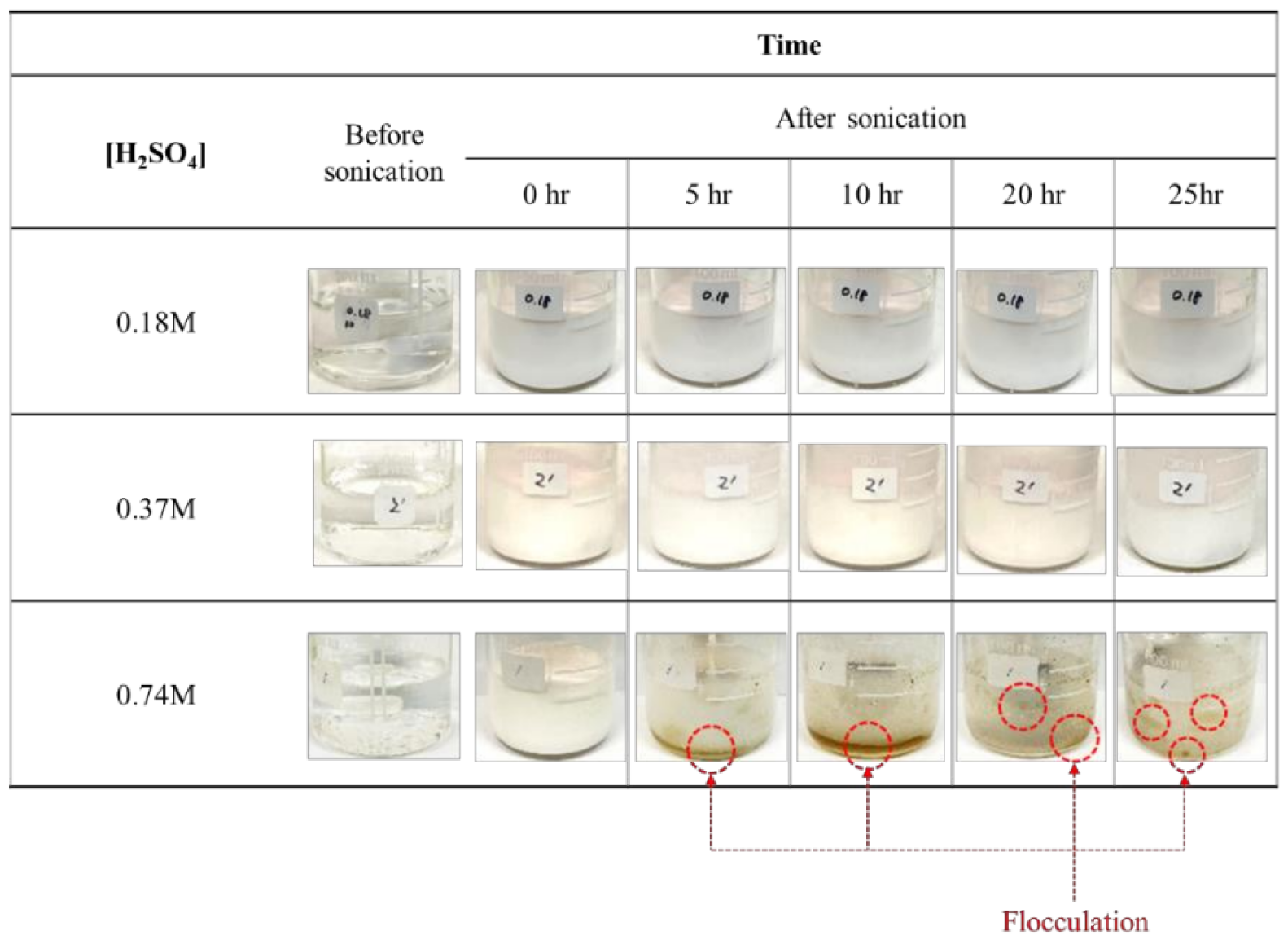

Figure 2. The phase change of the P-BED consisted of PFC-anionic surfactant- $\mathrm{H}_{2} \mathrm{SO}_{4}$ over time.

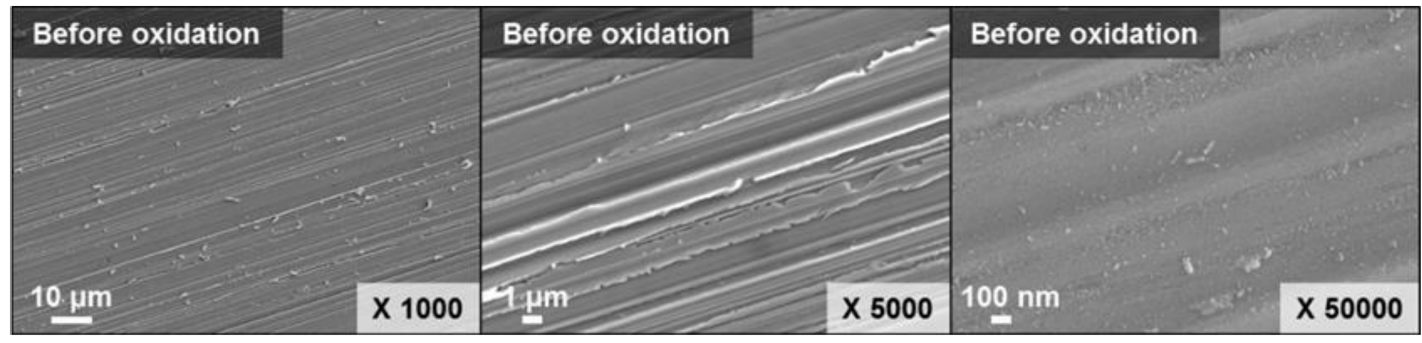

(a)

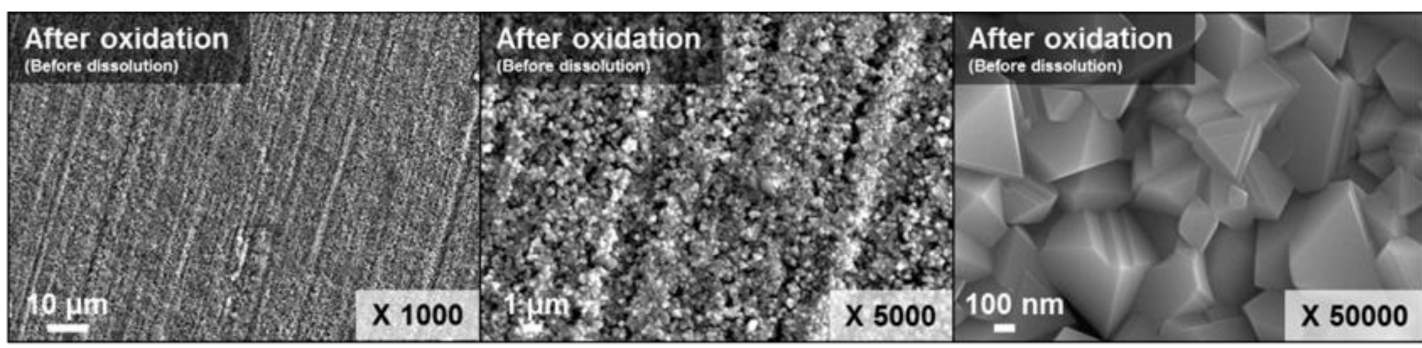

(b)

Figure 3. FE-SEM images of SUS304 specimen surface: (a) Before oxidation and (b) after oxidation.

Chromium oxide dissolves in an acidic condition, as shown in Equation (1). At $45^{\circ} \mathrm{C}$, the dissolution reaction was calculated by chemical equilibrium calculation program (HSC Chemistry 6.0), and it was confirmed that the reaction proceeds spontaneously. The reaction 
(1) proceeds as two successive steps, as shown in Equations (2) and (3) [20]. Especially, reaction (3) is known as the Guyard reaction. At the initial dissolution stage, $\mathrm{H}^{+}$ion involves in the dissolution reaction and promotes the dissolution of $\mathrm{Cr}_{2} \mathrm{O}_{3}$. They were also calculated by chemical equilibrium calculation program (HSC Chemistry 6.0).

$$
\begin{gathered}
\mathrm{Cr}_{2} \mathrm{O}_{3}+2 \mathrm{MnO}_{4}^{-}+\mathrm{H}_{2} \mathrm{O} \rightarrow 2 \mathrm{HCrO}_{4}^{-}+2 \mathrm{MnO}_{2} ; \\
\left(\triangle \mathrm{G}=-66.56 \mathrm{kcal}, \text { at } 45^{\circ} \mathrm{C}\right) \\
\mathrm{Cr}_{2} \mathrm{O}_{3}+1.2 \mathrm{MnO}_{4}^{-}+0.2 \mathrm{H}_{2} \mathrm{O}+1.6 \mathrm{H}^{+} \rightarrow 2 \mathrm{HCrO}_{4}{ }^{-}+2 \mathrm{Mn}^{2+} ; \\
\left(\triangle \mathrm{G}=-39.52 \mathrm{kcal}, \text { at } 45^{\circ} \mathrm{C}\right) \\
1.2 \mathrm{Mn}^{2+}+0.8 \mathrm{MnO}_{4}^{-}+0.8 \mathrm{H}_{2} \mathrm{O} \rightarrow 2 \mathrm{MnO}_{2}+1.6 \mathrm{H}^{+} ; \\
\left(\triangle \mathrm{G}=-27.04 \mathrm{kcal}, \text { at } 45^{\circ} \mathrm{C}\right)
\end{gathered}
$$

Based on the above dissolution reactions, it was decided to use $\mathrm{H}_{2} \mathrm{SO}_{4}-\mathrm{KMnO}_{4}$ as the decontamination agent and inject it into P-BED to remove the $\mathrm{Cr}_{2} \mathrm{O}_{3}$ layer during the dissolution test. The effect of the $\mathrm{H}_{2} \mathrm{SO}_{4}$ concentration in the P-BED on the dissolution performance was investigated when the $\mathrm{KMnO}_{4}$ concentration was constant at $0.13 \mathrm{mM}$. As shown in Figure 4, the weight loss of simulated oxide layer specimen increased with increasing $\mathrm{H}_{2} \mathrm{SO}_{4}$ concentration during the dissolution. This result could be explained by the dissolution reaction represented in Equation (2). In particular, the largest amount of $\mathrm{Cr}_{2} \mathrm{O}_{3}$ layer was dissolved when the $0.37 \mathrm{M}$ of $\mathrm{H}_{2} \mathrm{SO}_{4}$ was contained in the P-BED among the experimental conditions.

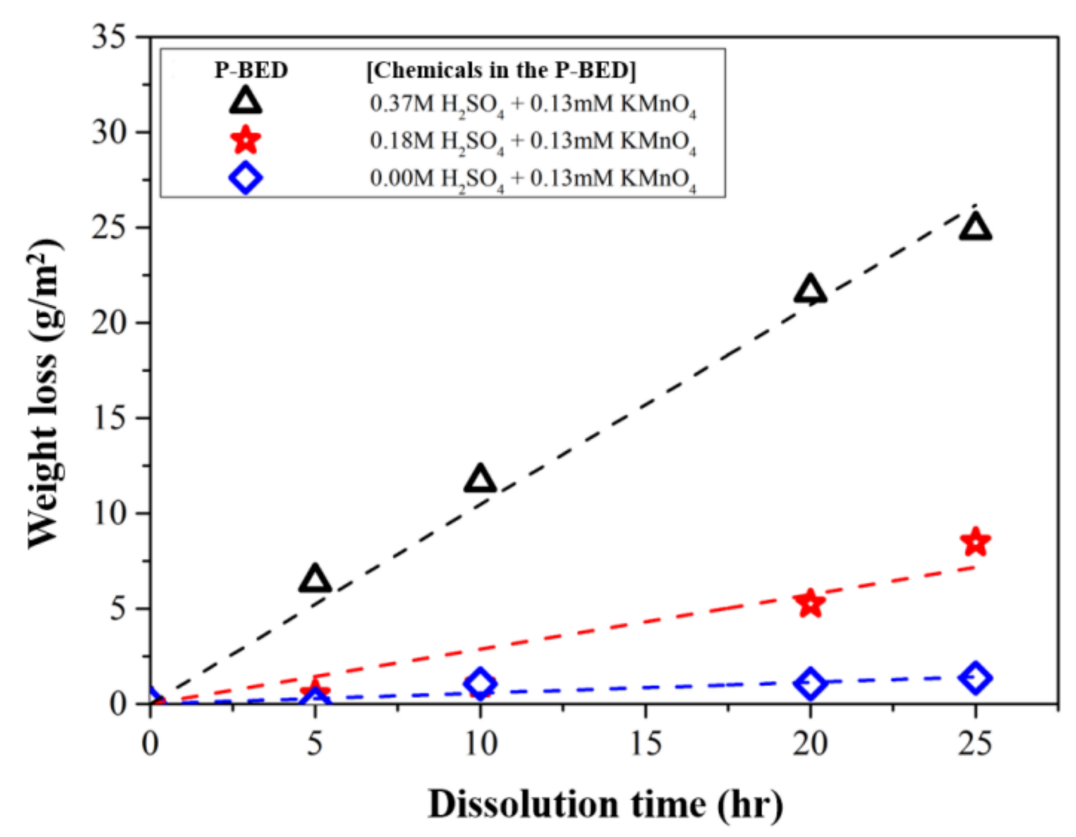

Figure 4. The weight loss of the specimens during the dissolution test for various concentrations of $\mathrm{H}_{2} \mathrm{SO}_{4}$ in the P-BED.

The oxide layers that remained on the specimen were observed after $25 \mathrm{~h}$ when the $\mathrm{H}_{2} \mathrm{SO}_{4}$ concentration was lower, as represented in Figure 5. In addition, more oxide layers were removed with increasing the dissolution time. The SEM result was agreed well with the result of the visual test, as illustrated in Figure 6. The more amounts of crystalline particles, which are the oxides, were maintained after the $25 \mathrm{~h}$ when the $\mathrm{H}_{2} \mathrm{SO}_{4}$ concentration was lower. In particular, the particles were not observed when the $\mathrm{H}_{2} \mathrm{SO}_{4}$ concentration was $0.37 \mathrm{M}$. From this result, it was also confirmed that the dissolution performance of $\mathrm{Cr}_{2} \mathrm{O}_{3}$ layers increased when the $\mathrm{H}_{2} \mathrm{SO}_{4}$ concentration in the P-BED was higher. The EDS result of the simulated specimen after dissolution is listed in Table 1. The atomic ratio of oxygen after $25 \mathrm{~h}$ of dissolution decreased to $7.96 \%$ when the $\mathrm{H}_{2} \mathrm{SO}_{4}$ 
concentration was $0.37 \mathrm{mM}$. However, the contents of the oxygen after $25 \mathrm{~h}$ of dissolution were $59.44 \%$ and $65.96 \%$ when the $\mathrm{H}_{2} \mathrm{SO}_{4}$ concentration was 0.18 and $0 \mathrm{mM}$, respectively. This was because the $\mathrm{H}^{+}$ion was concerned with the dissolution reaction of $\mathrm{Cr}_{2} \mathrm{O}_{3}$. Based on these results, it was determined that the optimized $\mathrm{H}_{2} \mathrm{SO}_{4}$ concentration in the P-BED is $0.37 \mathrm{M}$ for the effective dissolution performance among the experimental conditions. In addition, the above results were compared with the result of the $\mathrm{Cr}_{2} \mathrm{O}_{3}$ dissolution test using ozone conducted by Maroo [21]. They dissolved the $\mathrm{Cr}_{2} \mathrm{O}_{3}$ powder into the solution by injecting the ozone at $50{ }^{\circ} \mathrm{C}$, which is the similar temperature condition of this research. As a result, only $20 \%$ of the injected $\mathrm{Cr}_{2} \mathrm{O}_{3}$ were dissolved for $6 \mathrm{~h}$. From this, it was expected that the more amount of $\mathrm{Cr}_{2} \mathrm{O}_{3}$ layer can be removed within the same dissolution time if P-BED is applied compared with application of ozone.

\begin{tabular}{|c|c|c|c|c|c|}
\hline & \multicolumn{5}{|c|}{ Dissolution Time } \\
\hline $\begin{array}{l}\text { [Chemicals } \\
\text { in the P-BED] }\end{array}$ & $0 \mathrm{hr}$ & $5 \mathrm{hr}$ & $10 \mathrm{hr}$ & $20 \mathrm{hr}$ & $25 \mathrm{hr}$ \\
\hline 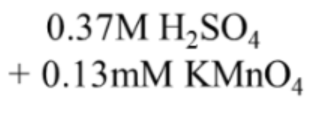 & 0 & & & & \\
\hline $\begin{array}{c}0.18 \mathrm{M} \mathrm{H}_{2} \mathrm{SO}_{4} \\
+0.13 \mathrm{mM} \mathrm{KMnO}_{4}\end{array}$ & 0 & 0 & & & \\
\hline $\begin{array}{c}0.00 \mathrm{M} \mathrm{H}_{2} \mathrm{SO}_{4} \\
+0.13 \mathrm{mM} \mathrm{KMnO}_{4}\end{array}$ & 10 & 0 & & & \\
\hline
\end{tabular}

Figure 5. The change in the specimen's surfaces during the dissolution test for various concentrations of $\mathrm{H}_{2} \mathrm{SO}_{4}$ in the P-BED.

Table 1. EDS (at X1000) results of the specimen after a $25 \mathrm{~h}$ dissolution test under various concentrations of $\mathrm{H}_{2} \mathrm{SO}_{4}$ in P-BED.

\begin{tabular}{|c|c|c|c|}
\hline \multirow[b]{2}{*}{ Element } & \multicolumn{3}{|c|}{ Atomic Percent (\%) } \\
\hline & $\begin{array}{c}0.37 \mathrm{M} \mathrm{H}_{2} \mathrm{SO}_{4} \\
+0.13 \mathrm{mM} \mathrm{KMnO}_{4} \\
\end{array}$ & $\begin{array}{c}0.18 \mathrm{M} \mathrm{H}_{2} \mathrm{SO}_{4} \\
+0.13 \mathrm{mM} \mathrm{KMnO}_{4}\end{array}$ & $\begin{array}{c}0.00 \mathrm{M} \mathrm{H}_{2} \mathrm{SO}_{4} \\
+0.13 \mathrm{mM} \mathrm{KMnO}_{4} \\
\end{array}$ \\
\hline $\mathrm{O}$ & 7.96 & 59.44 & 65.96 \\
\hline $\mathrm{Cr}$ & 17.07 & 17.96 & 15.96 \\
\hline $\mathrm{Fe}$ & 67.89 & 22.01 & 17.41 \\
\hline $\mathrm{Ni}$ & 7.08 & 0.58 & 0.66 \\
\hline Total & 100.00 & 100.00 & 100.00 \\
\hline
\end{tabular}




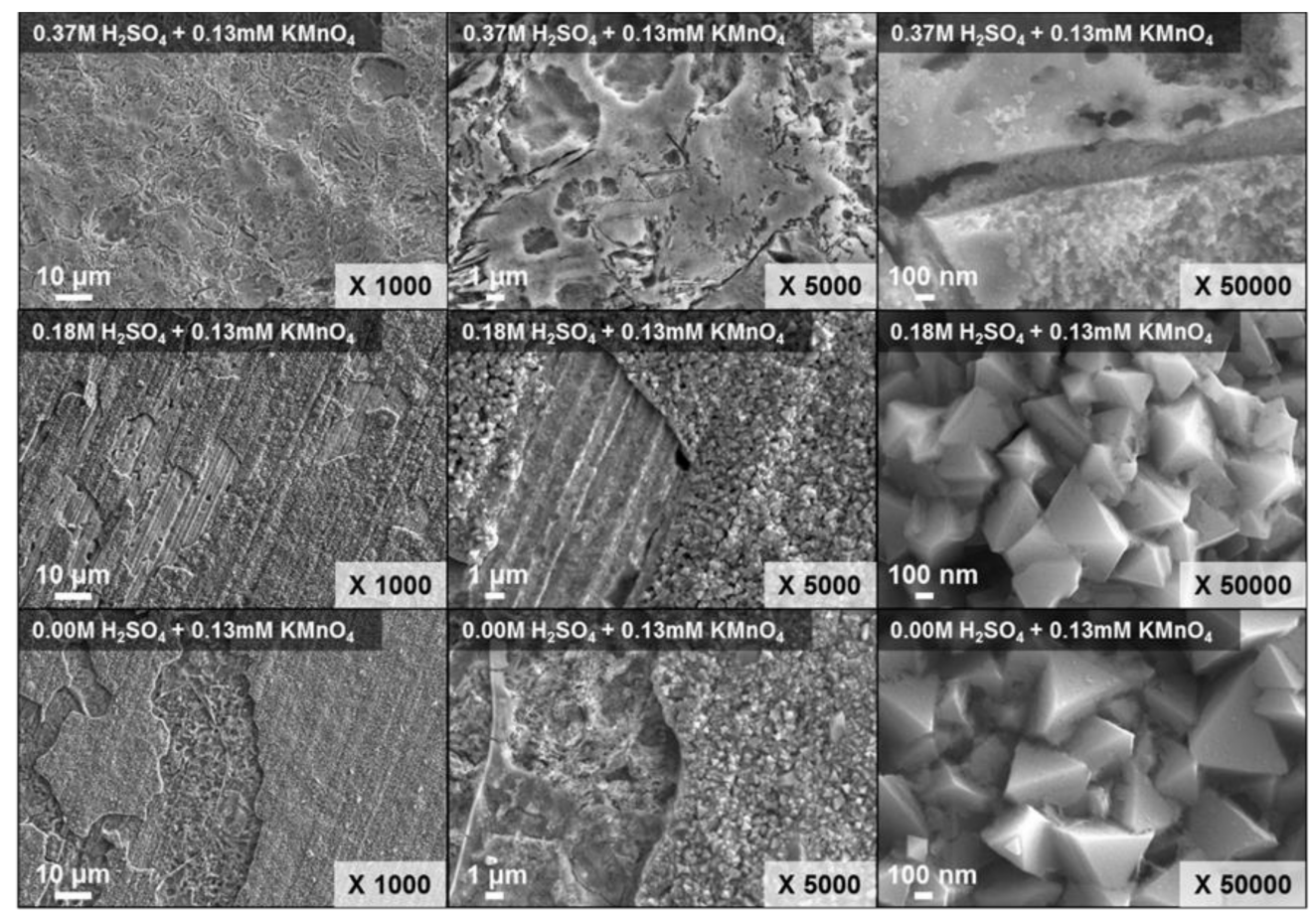

Figure 6. SEM images of the specimens after a $25 \mathrm{~h}$ dissolution test under various concentrations of $\mathrm{H}_{2} \mathrm{SO}_{4}$ in the $\mathrm{P}$-BED.

When the same concentration of $\mathrm{H}_{2} \mathrm{SO}_{4}$ and the various concentrations of $\mathrm{KMnO}_{4}$ were added in the P-BED, the weight loss of the simulated specimen over the dissolution time is illustrated in Figure 7. The photographs of the simulated specimens during the dissolution test are shown in Figure 8. As shown in Figure 7, the number of removed oxide layers increased as the concentration of $\mathrm{KMnO}_{4}$ increased from $0 \mathrm{mM}$ to $0.13 \mathrm{mM}$. Because the reaction (2) and (3) increased with increasing the concentration of $\mathrm{KMnO}_{4}$. This result can also be found in the photographs of the specimens in Figure 8. Especially, the oxide layers were fully removed after $25 \mathrm{~h}$ of dissolution when the $\mathrm{KMnO}_{4}$ concentration was $0.13 \mathrm{mM}$. Based on the result, the optimum concentration of $\mathrm{KMnO}_{4}$ in the $\mathrm{P}$-BED for the effective dissolution of the $\mathrm{Cr}_{2} \mathrm{O}_{3}$ layer was determined $0.13 \mathrm{mM}$ among the experimental condition.

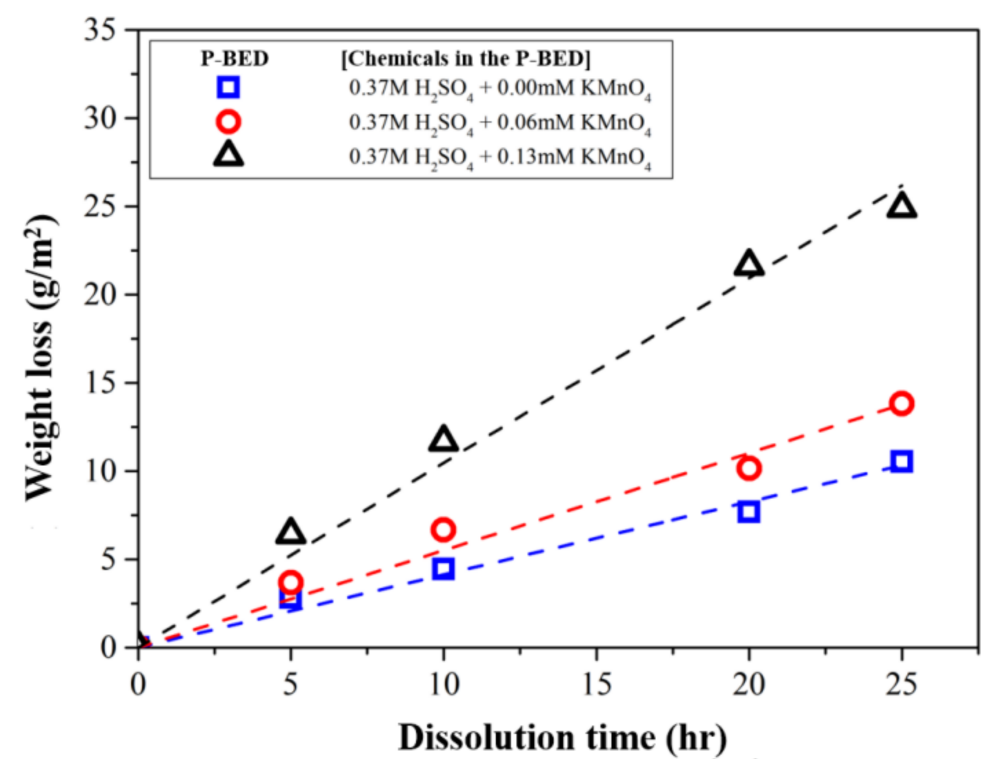

Figure 7. The weight loss of the specimens during the dissolution test for various concentrations of $\mathrm{KMnO}_{4}$ in the P-BED. 


\begin{tabular}{|c|c|c|c|c|c|}
\hline & \multicolumn{5}{|c|}{ Dissolution Time } \\
\hline $\begin{array}{l}\text { [Chemicals } \\
\text { in the P-BED] }\end{array}$ & $0 \mathrm{hr}$ & $5 \mathrm{hr}$ & $10 \mathrm{hr}$ & $20 \mathrm{hr}$ & $25 \mathrm{hr}$ \\
\hline $\begin{array}{c}0.37 \mathrm{M} \mathrm{H}_{2} \mathrm{SO}_{4} \\
+0.00 \mathrm{mM} \mathrm{KMnO}_{4}\end{array}$ & 0 & & & 0 & \\
\hline $\begin{array}{c}0.37 \mathrm{M} \mathrm{H}_{2} \mathrm{SO}_{4} \\
+0.06 \mathrm{mM} \mathrm{KMnO}_{4}\end{array}$ & 0 & & & & \\
\hline 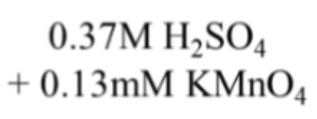 & & & & & \\
\hline
\end{tabular}

Figure 8. The change in the specimen's surfaces during the dissolution test for various concentrations of $\mathrm{KMnO}_{4}$ in the P-BED.

Figure 9 shows the morphology of the simulated specimens after $25 \mathrm{~h}$ of dissolution, when the concentrations of $\mathrm{H}_{2} \mathrm{SO}_{4}$ was $0.37 \mathrm{mM}$, and $\mathrm{KMnO}_{4}$ concentrations in the P-BED was 0 to $0.13 \mathrm{mM}$. The crystalline particles (which are the oxides) on the specimen decreased with increasing the concentration of $\mathrm{KMnO}_{4}$ in the P-BED. EDS results of the simulated specimens after $25 \mathrm{~h}$ of dissolution using P-BED was listed in Table 2 . The contents of oxygen decreased to $44.17 \%, 32.97 \%$, and $7.96 \%$ after the dissolution when the concentrations of $\mathrm{KMnO}_{4}$ in the P-BED were $0,0.06$, and $0.13 \mathrm{mM}$, respectively. These results were consistent with the results of weight loss, shown in Figure 7, and photographs of specimens, represented in Figure 8. In addition, a part of the oxide layer was removed even when the $\mathrm{KMnO}_{4}$ was absent in the P-BED, as shown in Figure 9. Based on the result, it was found that a portion of the oxide layers could also be removed by reaction with $\mathrm{H}^{+}$ions.

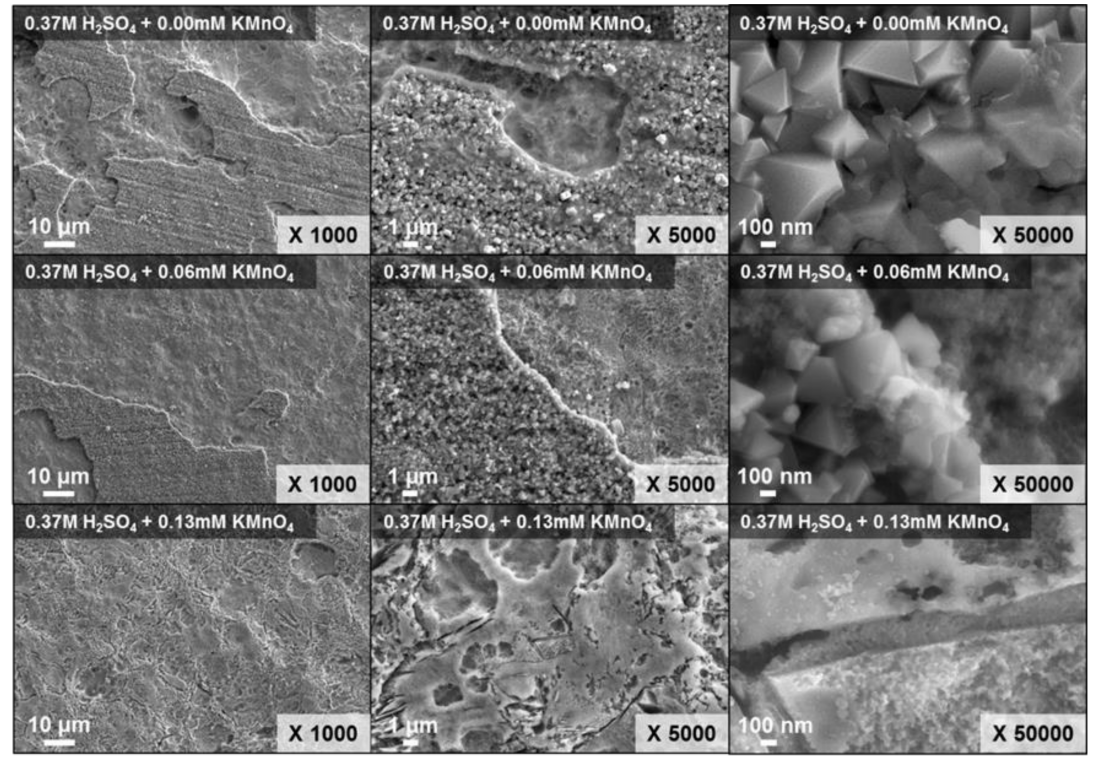

Figure 9. SEM images of the specimens after a $25 \mathrm{~h}$ dissolution test under various concentrations of $\mathrm{KMnO}_{4}$ in the P-BED. 
Table 2. EDS (at X1000) results of the specimen after a $25 \mathrm{~h}$ dissolution test under various concentrations of $\mathrm{KMnO}_{4}$ in P-BED.

\begin{tabular}{|c|c|c|c|}
\hline \multirow[b]{2}{*}{ Element } & \multicolumn{3}{|c|}{ Atomic Percent (\%) } \\
\hline & $\begin{array}{c}0.37 \mathrm{M} \mathrm{H}_{2} \mathrm{SO}_{4} \\
+ \\
0.00 \mathrm{mM} \mathrm{KMnO}_{4}\end{array}$ & $\begin{array}{c}0.37 \mathrm{M} \mathrm{H}_{2} \mathrm{SO}_{4} \\
+0.06 \mathrm{mM} \mathrm{KMnO}_{4}\end{array}$ & $\begin{array}{c}0.37 \mathrm{M} \mathrm{H}_{2} \mathrm{SO}_{4} \\
+0.13 \mathrm{mM} \mathrm{KMnO}_{4} \\
\end{array}$ \\
\hline $\mathrm{O}$ & 44.17 & 32.97 & 7.96 \\
\hline $\mathrm{Cr}$ & 16.23 & 9.80 & 17.07 \\
\hline $\mathrm{Fe}$ & 37.98 & 54.09 & 67.89 \\
\hline $\mathrm{Ni}$ & 1.61 & 3.15 & 7.08 \\
\hline Total & 100.00 & 100.00 & 100.00 \\
\hline
\end{tabular}

\subsection{P-BED Behaviors during the Dissolution of the Oxide Layer}

Figure 10 shows the photographs of the P-BED consist of PFC, anion surfactant, $0.37 \mathrm{M}$ $\mathrm{H}_{2} \mathrm{SO}_{4}$, and $0.13 \mathrm{mM} \mathrm{KMnO}_{4}$ before applying the ultrasonication process and during the oxide layer dissolution test. $\mathrm{H}_{2} \mathrm{SO}_{4}-\mathrm{KMnO}_{4}$ was injected in the P-BED because they were used as the decontamination agent in the PFC medium. The $\mathrm{H}_{2} \mathrm{SO}_{4}-\mathrm{KMnO}_{4}$ with a purple color was located at the top of the PFC-anionic surfactant $-\mathrm{H}_{2} \mathrm{SO}_{4}-\mathrm{KMnO}_{4}$ mixed solution before the ultrasonication. The reason is that the density of $\mathrm{H}_{2} \mathrm{SO}_{4}-\mathrm{KMnO}_{4}$ was lower than that of PFC, $1.75 \mathrm{~g} / \mathrm{cm}^{3}$ [6]. According to the pourbaix diagram, the purple color was caused by $\mathrm{MnO}_{4}{ }^{-}$ions [22]. After the ultrasonication process, $\mathrm{H}_{2} \mathrm{SO}_{4}-\mathrm{KMnO}_{4}$ was uniformly dispersed in the PFC, and the P-BED changed to a cloudy phase, as shown in Figure 10. After $25 \mathrm{~h}$ of dissolution, the flocculation and the separation of some agents were observed from the P-BED. The flocculated and separated agents were the used decontamination agent. The separated agent did not have a purple color, unlike before the dissolution test. Because the purple $\mathrm{MnO}_{4}{ }^{-}$ions in the agent were consumed during the $\mathrm{Cr}_{2} \mathrm{O}_{3}$ removal reactions indicated in Equations (1)-(3). The flocculation and separation of the used decontamination agent, however, were not observed when the dissolution of the oxide layer was not conducted, as shown in Figure 2. Through the results, it was confirmed that the P-BED became unstable as $\mathrm{MnO}_{4}{ }^{-}$ions were consumed during oxide layer dissolution.

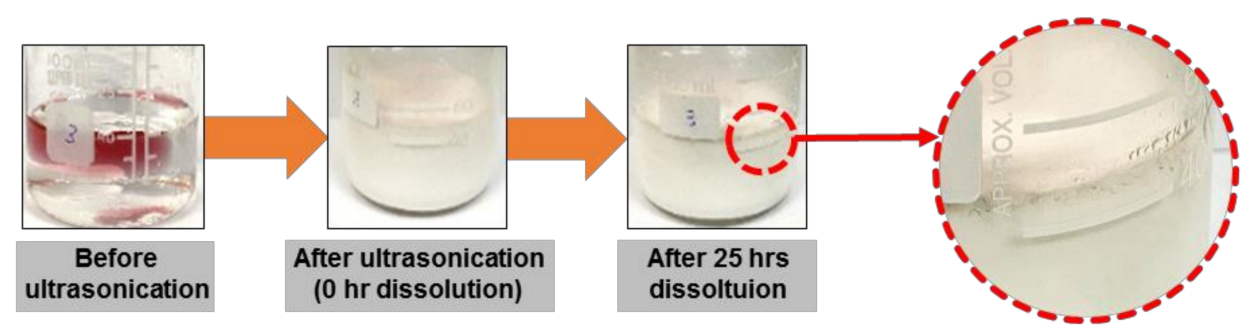

Figure 10. Photographs showing the formation change of the P-BED composed of PFC, anionic surfactant, $0.37 \mathrm{M} \mathrm{H}_{2} \mathrm{SO}_{4}$, and $0.13 \mathrm{mM} \mathrm{KMnO}_{4}$ before ultrasonication and during the dissolution test.

Based on the results, the behaviors of the P-BED during the dissolution of the oxide layer were suggested, as indicated in Figure 11. As shown in Figure 11a, the hydrophilic head of the anionic surfactant, which had the carboxyl group, formed an O-H bond with the water in the $\mathrm{H}_{2} \mathrm{SO}_{4}-\mathrm{KMnO}_{4}$ after the ultrasonication process. In addition, the P-BED was emulsified as the hydrophobic tail of the anionic surfactant interacted with PFC. As seen in Figure 11b, the number of bonds between the anionic surfactant and the water decreased as the P-BED became gradually unstable over time. However, the flocculation did not occur at this time, and the $\mathrm{H}_{2} \mathrm{SO}_{4}-\mathrm{KMnO}_{4}$ participated in the dissolution reaction of the oxide layer. The bond between the water and the surfactant decreased further over time, and the P-BED offered more activation sites for dissolution reaction. Therefore, oxides were dissolved in the metal ions. The metal ions coexisted with $\mathrm{H}^{+}, \mathrm{SO}_{4}{ }^{-}$, and $\mathrm{K}^{+}$ions 
in the decontamination agent of P-BED. Afterwards, the $\mathrm{H}_{2} \mathrm{SO}_{4}-\mathrm{KMnO}_{4}$ participated in the dissolution reaction of the oxide layer began to flocculate with each other, as shown in Figure 11c. After finishing the dissolution, the used decontamination agent containing various ions was finally separated, and they were located at the top of the P-BED as represented in Figure 11d. Due to the characteristic of P-BED, the used decontamination agent can be easily removed from the P-BED by scooping method after finishing the oxide layer dissolution. Therefore, the PFC and surfactant mixed solution located at the bottom can be reused for removing the oxide layers after re-injecting the decontamination agent and applying the ultrasonication process.

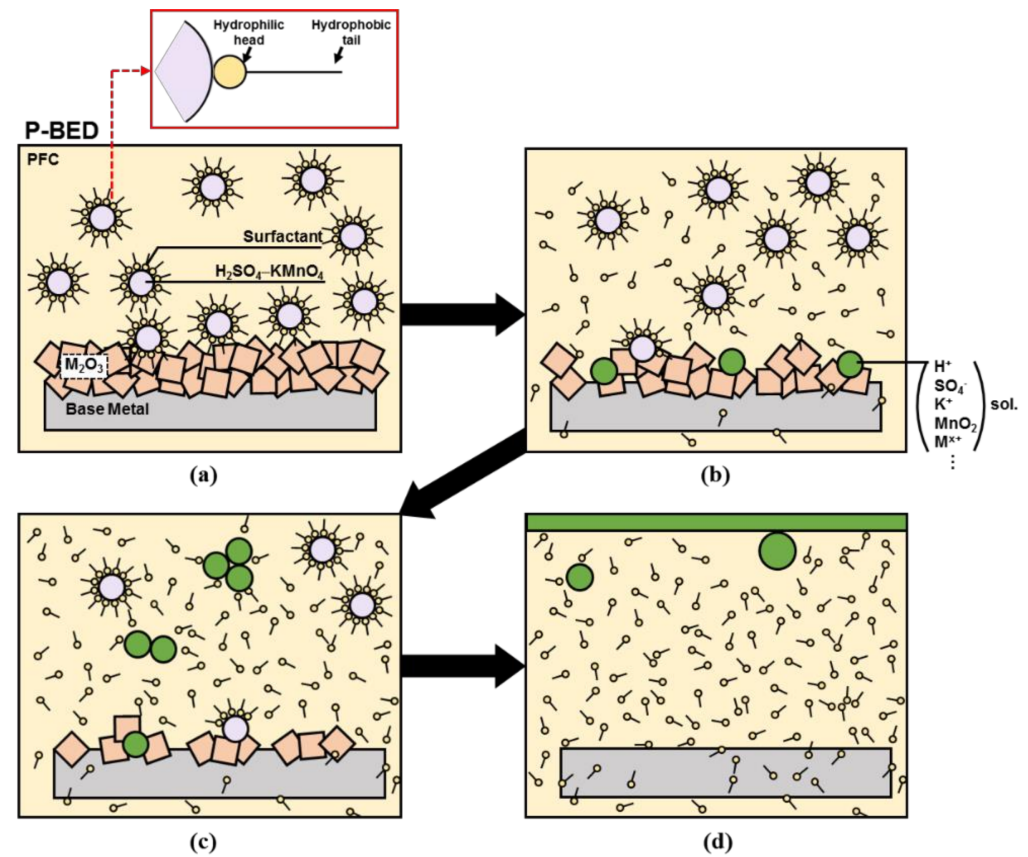

Figure 11. Schematic diagrams of the P-BED behaviors during oxide layer dissolution; (a) P-BED after ultrasonication process, (b) oxide layer dissolution by reaction with unstable P-BED, (c) $\mathrm{H}_{2} \mathrm{SO}_{4}-$ $\mathrm{KMnO}_{4}$ flocculation after participating the oxide layer dissolution reaction, and (d) separation of $\mathrm{H}_{2} \mathrm{SO}_{4}-\mathrm{KMnO}_{4}$ after finishing the oxide layer dissolution.

\section{Materials and Methods}

\subsection{Materials}

P-BED was composed of 93 vol\% of PFC (3M, PF-5058, St. Paul, MN, USA), 3 vol\% of anionic surfactant (Krytox 157FSM, Dupont, Wilmington, DE, USA) and 4 vol\% of a decontamination agent. The total volume of the P-BED is $50 \mathrm{~mL}$, and they were prepared in the bottle with a lid. The decontamination agent consisted of $\mathrm{H}_{2} \mathrm{SO}_{4}(98 \%, \mathrm{DAEJUNG}$, Siheung-si, Gyeonggi-do, Korea). When the dissolution test was performed, $\mathrm{KMnO}_{4}$ (>99.3\%, DAEJUNG, Siheung-si, Gyeonggi-do, Korea) was additionally injected into the decontamination agent. DI water (Direct- $\mathrm{Q}^{\circledR} 3 \mathrm{UV}$, Millipore, Burlinton, MA, USA) was used for preparing the decontamination agent. The concentrations of $\mathrm{H}_{2} \mathrm{SO}_{4}$ and $\mathrm{KMnO}_{4}$ in the P-BED were 0 to $0.74 \mathrm{M}$ and 0 or $0.13 \mathrm{mM}$, respectively.

\subsection{P-BED Preparation}

The P-BED was prepared through the process, as represented in Figure 12. Firstly, PFC-surfactant- $\mathrm{H}_{2} \mathrm{SO}_{4}$ and $\mathrm{KMnO}_{4}$ agent mixed solutions were prepared. The solution was stirred at $500 \mathrm{rpm}$ for $5 \mathrm{~min}$ using a magnetic stirrer (HSD 150-03P, MTOPS, Yangju-si, Gyeonggi-do, Korea,). After stirring, the ultrasonication process was applied to the mixed solution using ultrasonic (VC-505 Ultrasonic Processor, SONICS, Newtown, CT, USA). The decontamination agent in the PFC was dispersed homogeneously through this process. 
The application conditions of ultrasonic were 500 Watt of power, $20 \mathrm{kHz}$ of frequency, and $80 \%$ of amplitude. The ultrasonication process was conducted for $3 \mathrm{~min}$.

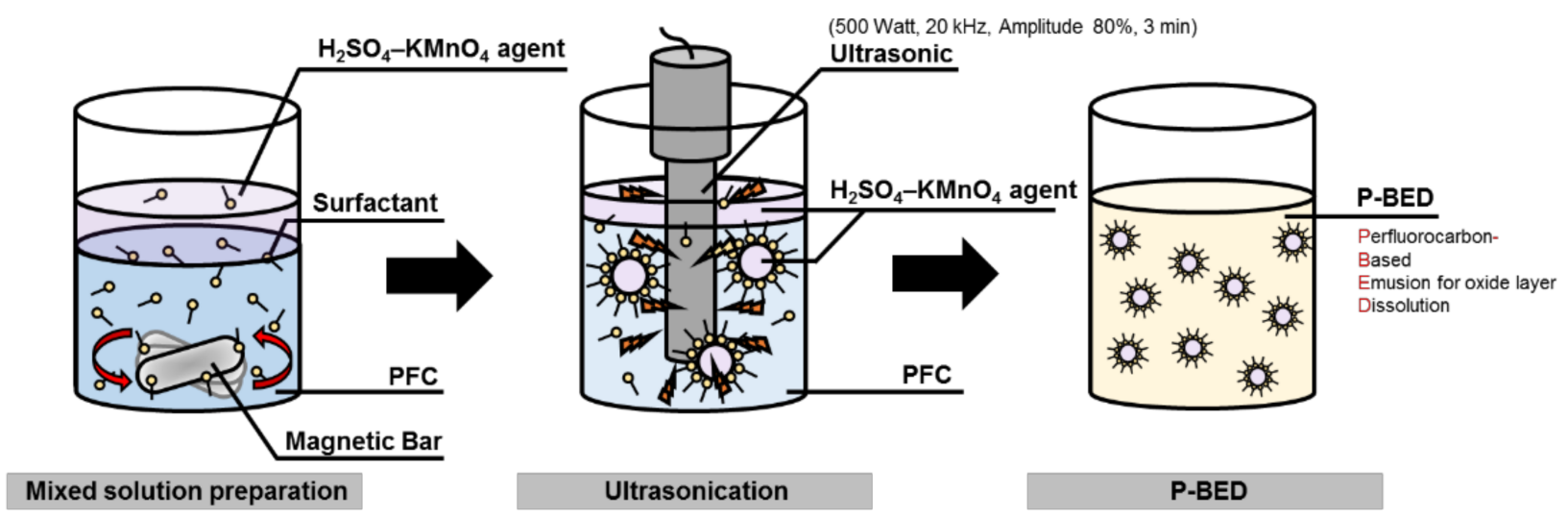

Figure 12. Preparation of P-BED.

\subsection{Dissolution Test}

The dissolution performances of P-BED containing $\mathrm{KMnO}_{4}$ were evaluated using the simulated oxide layer of the SUS304 specimen. The specimen was prepared by a hightemperature oxidation process using a muffle furnace (MF-12, Hanyang Science Equipment Co., Nowon-gu, Seoul, Korea). The high-temperature oxidation process was conducted at $800{ }^{\circ} \mathrm{C}$ for $32 \mathrm{~h}$. Before the oxidation process, the specimens were treated using 800 grit sizes of sandpaper. The simulated oxide layer mainly consisted of $\mathrm{Cr}_{2} \mathrm{O}_{3}$. The dissolution test was performed by immersing the simulated oxide layer specimen in the $50 \mathrm{~mL}$ of P-BED, while the P-BEDs were stirred at $250 \mathrm{rpm}$ using a magnetic stirrer (MTOPS, HSD15003P). The P-BEDs were stored in the bottle with the lid during the dissolution test. The temperature of P-BEDs was maintained at $45^{\circ} \mathrm{C}$. To compare the performance, the mass of the specimen was measured at $5,10,20$, and $25 \mathrm{~h}$, and the appearance change of the specimen was observed during the test. The weight loss was calculated using Equation (4).

Weight loss $=($ Initial specimen weight - specimen weight at time $\mathrm{t}) /($ surface area of specimen $),\left[\mathrm{g} / \mathrm{m}^{2}\right]$

\subsection{Analysis}

The bonding characteristics of the P-BED were analyzed using FTIR (ABB, MB3000). The P-BED was filtered using a PTFE syringe filter $(0.2 \mu \mathrm{m}$ pore size, Whatman, Maidstone, Kent, UK) before the FTIR analysis. The morphology of the simulated oxide layer specimens before and after the high-temperature oxidation was observed using FE-SEM (Merlin Compact, ZEISS, Oberkochen, Land Baden-Württemberg, Germany). In addition, the composition of the simulated oxide layer specimens was analyzed by EDS (ZEISS, Merlin Compact, ZEISS, Oberkochen, Land Baden-Württemberg, Germany). During the dissolution, the weight change of the simulated oxide layer specimen was measured using the electronic micro-balance (XS204, Mettler Toledo, Columbus, OH, USA).

\section{Conclusions}

A number of metallic equipment installed in the nuclear facilities are contaminated with radionuclides contained in the oxide layer during the operation. The radionuclides have been generally removed by dissolving the oxide layer using the chemicals in an aqueous solution. It, however, generates a large amount of radioactive liquid waste as a secondary waste after dissolving the oxide layers and contaminants. Therefore, the removal method for dissolution of the oxide layer using reusable chemicals called P-BED is suggested in this study. P-BED consists of PFC, anionic surfactant, $\mathrm{H}_{2} \mathrm{SO}_{4}$, and an oxidant or the reducing agent. An advantage of P-BED is that the P-BED can be reused the PFC and 
surfactant after easily removing the used decontamination agent located at the top of the spent P-BED. This is because the emulsion medium is easily separated over time, and the used decontamination agent can be separated from the P-BED. They can be removed by scooping from the top of the solution because the density of the decontamination agent is lower than PFC. Therefore, the P-BED can be effectively used for decontamination of metal equipment, and it can contribute to reducing the amount of radioactive waste generation.

FTIR result of P-BED revealed that the homogenous dispersion of $\mathrm{H}_{2} \mathrm{SO}_{4}$ in the PFC was caused by the interaction between the carboxyl group of anionic surfactants, and the water including $\mathrm{H}_{2} \mathrm{SO}_{4}$. The results of the dissolution test showed that the simulated oxide layer specimen was satisfactorily removed by applying the P-BED method. During the dissolution of the oxide layer, the dispersion stability of the P-BED gradually decreased, and the $\mathrm{H}_{2} \mathrm{SO}_{4}-\mathrm{KMnO}_{4}$ was separated from the PFC. In addition, it was confirmed that the $\mathrm{MnO}_{4}{ }^{-}$ions in the P-BED were consumed as participating in the dissolution reaction of $\mathrm{Cr}_{2} \mathrm{O}_{3}$. From the results, the behaviors of the P-BED during the dissolution of the oxide layer were illustrated. Based on the research result, it is possible to evaluate the oxide layer removal performance using the reused P-BED in the future.

Author Contributions: Conceptualization, N.C. and H.W.; methodology, N.C. and H.W., Formal analysis, N.C.; investigation, N.C., H.W. and H.E.; data curation, N.C., H.W. and C.J.; writing-original draft preparation, N.C. and H.W., writing- review and editing, N.C., H.W., S.K. and Y.K.; supervision, H.W. All authors have read and agreed to the published version of the manuscript.

Funding: This work was carried out under the Nuclear R\&D program (NRF-2017M2A8A5015144) funded by the Ministry of Science, ICT and Future Planning (MSIP) and Nuclear Research and Development Program (NRF-2018M2B2B1065634) funded by the Ministry of Science and ICT(MIST) of the Republic of Korea.

Institutional Review Board Statement: Not applicable.

Informed Consent Statement: Not applicable.

Data Availability Statement: Not applicable.

Conflicts of Interest: The authors declare no conflict of interest.

Sample Availability: Not applicable.

\section{References}

1. Provens, H. Primary circuit contamination in nuclear power plants: Contribution to occupational exposure. In Proceedings of the Towards Harmonisation of Radiation Protection in Europe: European IRPA Congress 2002, Florence, Italy, 8-11 October 2002.

2. Vinod, K.; Rajeev, G.; Raman, C.; M, S.; Rakesh, K.S. Chemical, biological, radiological, and nuclear decontamination: Recent trends and future perspective. J. Pharm. Bioallied Sci. 2010, 2, 220-238.

3. Remark, J.F. A Review of Plant Decontamination Methods; NP-6169; EPRI: Palo Alto, CA, USA; Marietta, GA, USA, 1989.

4. Jeikwon, M.; Seonbyung, K.; Wangkyu, C.; Byungseon, C.; Dongyoung, C.; Bumkyoung, S. The Status and Prospect of Decommissioning Technology Development at KAERI. JNFCWT 2019, 17, 139-165.

5. Wen-Tien, T.; Horng-Ping, C.; Wu-Yuan, H. A review of uses, environmental hazards and recovery/recycle technologies of perfluorocarbons (PFCs) emissions from the semiconductor manufacturing processes. J. Loss Prev. Process. Ind. 2002, 15, 65-75.

6. Charles, D.A. Fluorinated gases for semiconductor manufacture: Process advances in chemical vapor deposition chamber cleaning. J. Fluor. Chem. 2003, 122, 105-112.

7. Hui-Jun, W.; Gye-Nam, K.; Chung-Hun, J.; Jin-Ho, P.; Won-Zin, O. PFC Ultrasonic Decontamination Efficiency on the Various Types of Metal Specimens. J. Korean Radioact. Waste Soc. 2005, 3, 293-300.

8. PF-5058. Available online: Multimedia.3m.com/mws/media/244053O/performance-fluid-pf-5058-product-information.pdf (accessed on 11 January 2021).

9. Ilie, S.; Setnescu, R.; Teissandier, B. Chemical and Radiolytical Characterization of Perfluorocarbon Fluids Used as Coolants for LHC Experiments: Radiolysis Effect in Perfluorohexane Fluids; CERN-TS-Note-2007-005; CERN: Geneva, Switzerland, 2007.

10. Arthur, E.D.; Robert, K.; Jason, A.; Justin, D.; Josh, J.; Adam, K. Separation and Extraction of Plutonium in Mixed Waste; INIS-US-0199; Bartlett Services, Inc.: Plymoufh, MA, USA, 2002.

11. Huijun, W.; Kyenam, K.; Wangkyu, C.; Chonghun, C. A Study on the Decontamination of Radioactively Contaminated Facility by the PFC Spray Method. In Proceedings of the Korean Society of Environmental Engineers 2007 Autumn Conference, Chuncheon, Korea, 11-12 November 2007. 
12. Guoshen, S.; Chenghong, J.; Chao, L.; Xuejiao, S.; Xuan, Y.; Ziliang, D.; Kai, Y.; Zhuang, L. TaOx decorated perfluorocarbon nanodroplets as oxygen reservoirs to overcome, tumor hypoxia and enhance cancer radiotherapy. Biomaterials 2017, 112, 257-263.

13. Ulrich, F.; Zhaoping, D.; Hendrik, H.; Sebastian, J.; Gaby, R.; Christoph, J.; Rolf, S.; Jürgen, S. In Vivo Monitoring of Inflammation After Cardiac and Cerebral Ischemia by Fluorine Magnetic Resonance Imaging. Circulation 2008, 118, 140-148.

14. Paul, E.H.; Henrik, G.K.; Veronica, V.; James, B.B. Vibrational and Electronic Spectroscopy of Sulfuric Acid Vapor. J. Phys. Chem. A 2003, 107, 1112-1118.

15. David, F.C.; Jeffrey, R.; Watts, R.O. The Infrared Absorption Spectrum of Water. Aust. J. Phys. 1982, 35, $623-638$.

16. Andra, D.; Tatiana, T.; Adriana, S.; Ionut, R.A.; Simona, N.; Viorel, N.; Angela, S.; Mihail-Lucian, P.; Mihaela, O.R. Spectroscopic Characterization of Emulsions Generated with a New Laser-Assisted Device. Molecules 2020, 25, 1729.

17. Hong, Z.; Stephen, G.W. Teflon AF Materials. Topics Curr. Chem. 2012, 308, 307-338.

18. Mohammad, S.C.; Wenshan, Z.; Shalini, K.; John, H.; Xingcai, Z.; Pradip, D.; David, A.W.; Rainer, H. Dendronized fluorosurfactant for highly stable water-in-fluorinated oil emulsions with minimal inter-droplet transfer of small molecules. Nat. Commun. 2019, $10,4546$.

19. David, J.M.; Sied, M.J. Improving emulsion formation, stability and performance using mixed emulsifiers: A review. Adv. Colloid Interface Sci. 2018, 251, 55-79.

20. Pick, M.E. Development of nitric acid permanganate pre-oxidation and its application in POD process for PWR decontamination. In Proceedings of the Decontamination of Nuclear Facilities, Toronto, ON, Canada, 19-22 September 1982.

21. Maroo, S.; Chandramohan, P.; Srinivasan, M.P.; Velmurugan, S. Chemical dissolution of iron substituted chromium oxide by dissolved ozone. Progress Nuclear Energy 2020, 120, 103189. [CrossRef]

22. Widya, E.K. Modification of Carbon Felt for Construction of Air-Breathing Cathode and Its Application in Microbial Fuel Cell; Institut teknologi Bandung, Material Chemistry, Université Montpellier: Montpellier, France, 2019. 